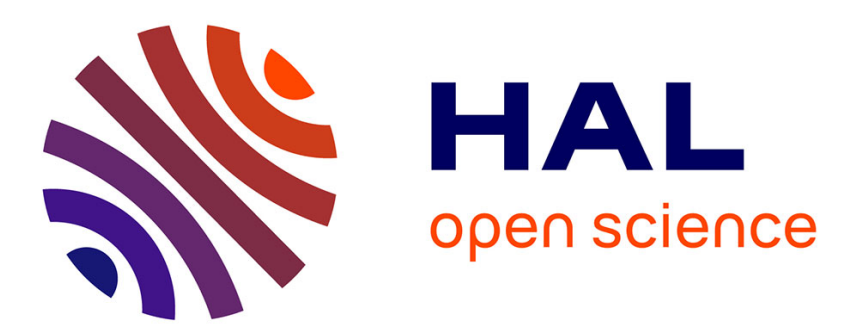

\title{
Benchmarking computational methods and influence of guest conformation on chirogenesis in zinc porphyrin complexes
}

\author{
Irina Osadchuk, Victor Borovkov, Riina Aav, Eric Clot
}

\section{To cite this version:}

Irina Osadchuk, Victor Borovkov, Riina Aav, Eric Clot. Benchmarking computational methods and influence of guest conformation on chirogenesis in zinc porphyrin complexes. Physical Chemistry Chemical Physics, 2020, 22 (19), pp.11025-11037. 10.1039/d0cp00965b . hal-02617464

\section{HAL Id: hal-02617464 \\ https://hal.umontpellier.fr/hal-02617464}

Submitted on 25 May 2020

HAL is a multi-disciplinary open access archive for the deposit and dissemination of scientific research documents, whether they are published or not. The documents may come from teaching and research institutions in France or abroad, or from public or private research centers.
L'archive ouverte pluridisciplinaire HAL, est destinée au dépôt et à la diffusion de documents scientifiques de niveau recherche, publiés ou non, émanant des établissements d'enseignement et de recherche français ou étrangers, des laboratoires publics ou privés. 


\section{Benchmarking Computational Methods and Influence of Guest Conformation on Chirogenesis in Zinc Porphyrin Complexes}

Received 00th January 20xx, Accepted 00th January 20xx DOI: $10.1039 / x 0 x x 00000 x$

\begin{abstract}
Irina Osadchuk, ${ }^{a, b}$ Victor Borovkov, ${ }^{\text {a,c }}$ Riina Aav ${ }^{\text {a }}$ and Eric Clot ${ }^{\text {b }}$
Circular dichroism (CD) is a convenient and widely used tool for investigating structures of chiral molecules. However, the unambiguous simulation of CD spectra is not a trivial task, because the accuracy of theoretical calculations depends on the nature of the system. In the present work, the induced CD spectra of six zinc porphyrin complexes with chiral guests were simulated by using different DFT methods. The best agreement between theoretical and experimental results for the Soret (B) band absorption region was achieved with the $\omega B 97 X-D, C A M-B 3 L Y P$, and M06-2X functionals with implicit inclusion of solvent effects (SMD model). Also, a good correlation between the simulated and experimental spectra was obtained with the DZVP basis sets, however a more accurate simulation of the length- and velocity rotational strengths needed larger TZVP basis sets. Additionally, the conformation of the chiral guest influences the chirogenic mechanism.
\end{abstract}

\section{Introduction}

Porphyrins are well-known as a chemical class of cyclic tetrapyrrolic compounds with four pyrrole subunits interconnected at their $\alpha$-carbon atoms via the methine bridges. Deprotonated porphyrins are dianionic and able to bind almost all main group metal ions to produce coordinated planar or non-planar complexes with one or two axial positions of the metal complex unoccupied. Such complexes are quite robust in diverse media and resistant to both the reductive and oxidative decompositions in most cases. Therefore, due to their structural stability and catalytic properties, metal porphyrins found a widespread use in natural and artificial systems. For example, in living organisms they are involved in a wide variety of important biological processes: electron transfer, enzymatic oxidation, light harvesting, substrate binding, oxygen transport and storage, etc. ${ }^{1,2}$ Besides, the porphyrin complexes are effectively applied in artificial photosynthesis, ${ }^{3-5}$ small molecules activation, ${ }^{5}$ oxygen and hydrogen evolution reactions ${ }^{6,7}$ and others. ${ }^{8}$ They also serve as well-established homogeneous catalysts for various reactions including epoxidation, sulfoxidation, hydroxylation, and carboxylation. ${ }^{5,9,10}$

Another important feature of porphyrin complexes is their

a. Department of Chemistry and Biotechnology, Tallinn University of Technology, Akadeemia tee 15, Tallinn 12618, Estonia.

b. ICGM, University of Montpellier, CNRS, ENSCM, Montpellier, France.

c. College of Chemistry and Materials Science, South-Central University for Nationalities, 182 Minzu road, Hongshan, Wuhan 430074, China.

Electronic Supplementary Information (ESI) available: [details of any supplementary information available should be included here]. See DOI: $10.1039 / \mathrm{x} 0 \times x \times 0000 x$ aromaticity. From a total of $26 \pi$-electrons, $18 \pi$-electrons form a planar and continuous cycle, thus the metal porphyrins possess strong magnetic and electric dipole moments exhibiting absorption on a wide wavelength range. This feature and the ability to form supramolecular assemblies with other molecules allow the use of porphyrins and their analogues as chemical and chirality sensors. ${ }^{8,11-14}$ Recently, much attention has been paid to chirogenic processes. Among them the induced chirality, where a chiral guest determines the stereochemistry of the entire host-guest system by binding to achiral metal porphyrins, has found various important applications. ${ }^{12-25}$

Initially, mono-porphyrins were used as chiral sensors, further bis- and tris-porphyrins as well as corresponding supramolecular assemblies were also applied for this purpose. ${ }^{26-33}$ Generally, the chirality of the system is probed by circular dichroism (CD) spectroscopy. ${ }^{12,20-23}$ Recently, a combination of experimental and computational studies on the complexation of a chiral zinc(II) porphyrin tweezer with achiral aliphatic diamines highlighted a critical role played by the diamine guest in modulating the relative orientation of the two porphyrin rings and hence in coupling the electronic transition moments. ${ }^{34,35}$ However, this phenomenon is absent in mono-porphyrins and the shape of the CD spectra is essentially dictated by the geometry of the host-guest adduct. So far, various computational strategies have been designed to model the corresponding CD spectra observed for various experimental systems. ${ }^{36-39}$

In the present work, different approaches in the framework of density functional theory (DFT) were tested for simulating the induced $C D$ spectra of porphyrin chromophores upon interaction with chiral guests. Previously, it was reported that the accuracy of simulated spectra depends on the type of the 
system used ${ }^{39-41}$ and class of the electronic excitations. ${ }^{42-45}$ Based on the experimental results obtained for six complexes consisting of monomeric zinc porphyrins and chiral amino acid derivatives, the performances of varying functionals, basis sets and solvation models are discussed. Calculations showed that not only chirality of the guest, but also its conformation determines the shape of the CD spectra. Moreover, it was found that, in the case of guest molecules with a rigid structure, the CD spectral simulation of the lowest-energy conformer resulted in a good agreement with the corresponding experimental data, since the latter made up more than $70 \%$ of the Boltzmann distribution.

\section{Results and discussion}

\section{$1^{\circ}$ Model systems}

Six complexes have been chosen on the basis of host-guest assemblies obtained by Mizutani et al. ${ }^{46,47}$ The complexes are formed by three monomeric zinc porphyrins (hosts) and four amino acid derivatives (guests) shown in Figure 1. In order to simplify the modelled systems, the corresponding ethyl peripheral substituents were changed to the methyl groups. It is assumed that the homologues alkyl substituents of similar electronic and steric influences have a negligible effect on the chiroptical properties. ${ }^{48-51}$

Host A, with two hydroxynaphtyl groups at the 5-,15-meso positions, is able to form hydrogen bonds with the guests. With this host, four supramolecules were modelled using alanine, leucine, and phenylalanine methyl esters (Ala-OMe, Leu-OMe, and Phe-OMe, respectively), as well as leucinol as the corresponding guests. In addition to coordination of the amino group with the $\mathrm{Zn}$ ion of the porphyrin, all these guests form a hydrogen bond with the hydroxyl group of the host.

\section{Guests:}

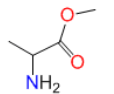

Ala-OMe

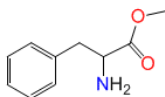

Phe-OMe

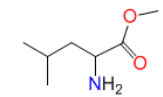

Leu-OMe

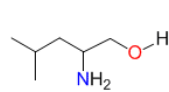

Leucinol
Hosts:

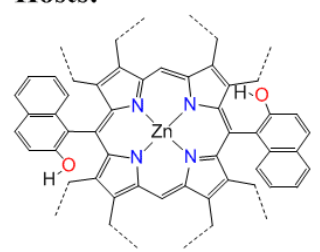

A

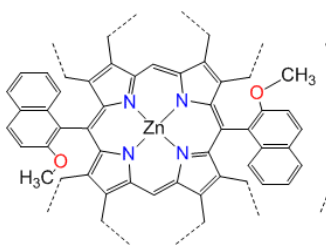

B

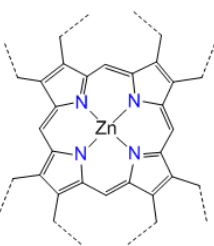

C
Figure 1. Guests and hosts used for modelling the complexes. Experimental CD spectra were measured for the complexes with ethyl groups at the porphyrin's $\beta$-positions (dashed lines), but for modelling the ethyl groups were replaced with methyl groups.
However, this interaction is weaker in the case of leucinol. Erreur! signet non défini. As hosts $B$ and $C$ do not have hydrogen bond donating groups, only the Phe-OMe containing host-guest complexes were modelled as the $\pi-\pi$ interactions between the porphyrin and the aromatic substituents of the guest are considered as a potential source of secondary interactions.

For the four systems (A/Leu-OMe, A/Phe-OMe, A/S-leucinol and $\mathrm{C} / \mathrm{Phe}-\mathrm{OMe}$ ), the corresponding experimental $\mathrm{CD}$ spectra are shown in Figure 2. The experimental ${ }^{46,47}$ and calculated values for selected spectral parameters for the six systems studied are given in Table 1.

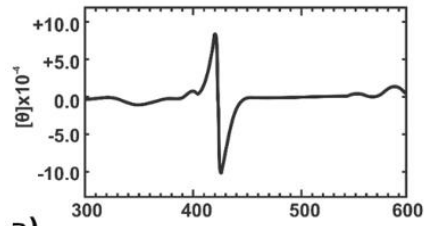

a)

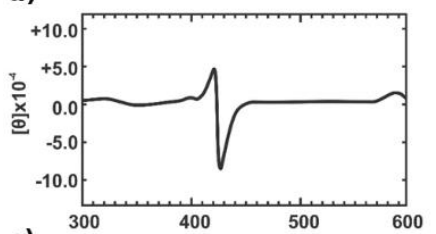

c)

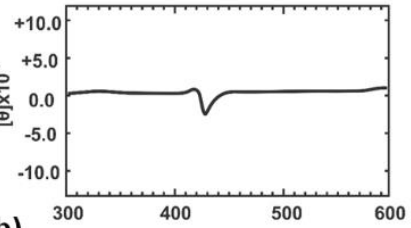

b)

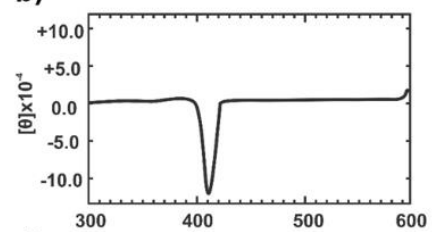

d)

Figure 2. Experimental CD spectra of a) Host A/L-Leu-OMe, b) Host A/S-Leucinol, c) Host A/L-Phe-OMe, d) Host C/L-Phe-OMe Copyright 1993 and 1994 American Chemical Society.

\section{$2^{\circ}$ Computational details}

In this work conformational search and geometry optimization were performed using $\left.\mathrm{RI}^{52-54}-\mathrm{BP} 86^{55,56-D 3^{57} / \text { def2-SV(P) }}\right)^{58}$ implemented in Turbomole6.5 59,60 The RI-BP86/def2-SV(P) level of theory was recommended as a fast and reliable method for treating systems containing metal ions. ${ }^{61,62}$ The use of dispersion correction is necessary in the case of systems containing noncovalent interactions. ${ }^{57,62,63}$ To confirm that the optimized geometry corresponds to a local minimum, the respective vibrational frequencies were calculated using the same program and level of theory. For each systems several conformations of the host-guest interaction were considered as starting geometries and several different conformers were obtained. In order to get a more accurate energy value, a single point calculation was done using the RI-BP86/def2TZVP64 level of theory and $\operatorname{COSMO}^{65}$ solvent model. The information for the various resulting complexes is given in $\mathrm{SI}$ (Table S1 for relative energies of the conformers and file Geom.xyz for the geometries).

The CD spectra were simulated using the Gaussian $16^{66}$ software and TD-DFT method. ${ }^{67-69}$ The first six excited states were calculated in order to ensure that both the $\mathrm{Q}$ - and $\mathrm{B}$ band regions of the spectrum are covered. The GGA, metaGGA, hybrid-GGA and long-range-corrected functionals were applied, since it was reported that these functionals perform 
differently depending on the type of the system ${ }^{39-41}$ and class of the electronic excitations. ${ }^{42-45}$ Moreover, it was shown that if the electronic excitation has a charge transfer character, performance of the functional depends upon the spatial overlap between the occupied and virtual orbitals involved in the excitations. ${ }^{70-73}$ Thus, for the simulations, eight functionals (PBE, ${ }^{74,75}$ BH\&HLYP, ${ }^{55,76-78}$ B3LYP, ${ }^{55,77-79}$ M06, ${ }^{80}$ M06-2X, ${ }^{80}$ CAM-B3LYP, ${ }^{81} \omega B 97 X-D^{82}$ and $L C-\omega$ HPBE $^{83}$ ) were chosen. All these eight functionals have been successfully applied for TDDFT simulations ${ }^{44,45,73,84-88}$ including simulations of the $C D$ spectra of metal complexes. ${ }^{89-99}$

In addition to the functionals, two basis sets of different sizes: cc-pVDZ100-102 and cc-pVTZ42,91,100-102 were considered. As reported previously, for UV and CD spectra simulations the double-zeta basis set is considered to be accurate. ${ }^{84,90}$ However, cc-pVTZ was also tested, since upon using the triple zeta basis set, a better agreement was obtained with the experimental energies for channel rhodopsins ${ }^{103}$ and bis(chelate) copper(I) guanidine-quinoline complex. ${ }^{91}$ Moreover, it was reported that the basis sets of at least triple zeta quality is needed for calculations of the rotatory strengths. ${ }^{87,104,105}$ Additionally, in many works it was stated that the use of diffuse functions is essential for accurate UV and CD spectra simulations. ${ }^{87,105-107}$ However, researches on zinc complexes of porphyrin demonstrated that polarization and diffuse functions have only a minor effect on TD-DFT excitation energies of tetrapyrrolic compounds. ${ }^{108,109}$

Finally, the CD spectra were simulated in a gas phase and in chloroform to evaluate the influence of solvent. To include implicit solvent effects, Polarizable Continuum Model (PCM) ${ }^{110}$ and Solvation Model based on Density (SMD) ${ }^{111}$ continuum models were used. Both these continuum models were successfully applied in TD-DFT simulations. ${ }^{88,90,112-114}$ Indeed, there are contradictory results on the solvent role on $C D$ spectral simulations. While, in some cases it was stated that the simulated $C D$ spectra were very sensitive to the solvent used, ${ }^{38,115,116}$ there are other examples reporting that inclusion of the solvent effects did not improve the agreement with the experimental spectra. ${ }^{88,90}$ The CD spectra were visualized using GaussView $6 .{ }^{117}$ For spectral building a bandwidth of $0.1 \mathrm{eV}$ was used as it had the best agreement with the experimental spectra (Figure S1). The rotatory strengths were calculated on the basis of the dipole velocity formalism (since it is origin independent). ${ }^{105}$

\section{$3^{\circ}$ Performance of Functionals}

The choice of the functional is the most important component in CD spectra simulations, ${ }^{42,91}$ since the accuracy of calculations strongly depends on the system ${ }^{39-41}$ and class of electronic excitations. ${ }^{42-45}$ Moreover, the accuracy may vary with the different regions of the spectrum. ${ }^{89}$ The geometry and basis set have less influence on the TD-DFT results than the functional. ${ }^{91,118}$
To test the functionals, the $C D$ spectra were first simulated only for the lowest-energy conformer of each porphyrin-guest complexes, since in all cases, this conformer made up more than $70 \%$ of the Boltzmann distribution (Table S1). The inclusion of the less stable conformers in the averaged spectra is presented at the end of the manuscript. In total, eight functionals were used as follows: one GGA functional (PBE) and seven hybrid functionals. The latter included two hybridGGA functionals with different portion of the exact exchange (BH\&HLYP (50\%) and B3LYP (20\%)), two hybrid-meta functionals from the Minnesota family accounting for the short and medium-range of dispersion corrections and containing different portions of exact exchange (M06 (27\%) and M06-2X (54\%), and three long-range-corrected functionals (CAMB3LYP, $\omega B$ 97X-D and LC- $\omega$ HPBE). All these eight functionals were previously successfully used for TD-DFT simulations including $C D$ spectra of metal complexes. ${ }^{89,90}$ The test calculations were performed using the cc-pVDZ basis set, since, as shown previously, the double-zeta basis set was accurate enough for UV and CD spectral simulations. ${ }^{84,90,116}$ Also, to include the implicit solvent effects, the SMD continuum model was used. For all the cases, the six first excited states were calculated (Table S2). In general, the CD spectra simulated using the above mentioned functionals, except PBE, have similar shapes and agree well with the experimental spectra (Figures 3 and S2).46,47

3.1 ${ }^{\circ}$ Simulation of the Q-bands region. The UV and CD spectra of porphyrins and their complexes typically have two absorption regions: the $500-650 \mathrm{~nm}$ region corresponding to the $Q$ bands and the $400-450 \mathrm{~nm}$ region corresponding to the $B$ band, ${ }^{119,120}$ with two electronic transitions in each band. ${ }^{95,120-122}$ As a result of the forbidden character of the $Q$ electronic transitions and vibrational borrowing from the allowed $B$ transition, $Q$ bands, when observed in the $C D$ spectra of porphyrins, have relatively small intensities. ${ }^{120}$ In the present work, since the vibrational contribution into the $C D$ spectra was not considered, the simulated spectra show only one very small band in this region (Figure 3 and Table S2). For all the abovementioned hybrid functionals excepting LC- $\omega$ HPBE, the $Q$ bands are located in the region of 540-600 $\mathrm{nm}$ (Table S2), while LC- $\omega$ HPBE shifts the $Q$ bands to $640 \mathrm{~nm}$. In the experimental $C D$ spectra, the $Q$ band peaks are positive, albeit weak and this is reproduced in the calculations (Table S2). According to Mizutani, ${ }^{46,47}$ the absorption maxima are situated at about $590 \mathrm{~nm}$. However, a more detailed comparison is hampered by the fact that the experimentally measured bands are very weak and the detailed information is not available.

3.2 Simulation of the B-band region. The B-band region (400$450 \mathrm{~nm}$ ) is computed to be shifted by the hybrid functionals, yet the shapes are quite similar (except for PBE). The main difference among the functionals is the position of the Cotton effect and the rotational strength (Figure 3, Table 1). In full agreement with the experimental data the positive and 
negative $C D$ signals were obtained for the following

Table 1. Cotton effect positions $\left(\lambda_{\max / \mathrm{min}}, \mathrm{nm}\right)$ and rotational strength $(R, \mathrm{cgs})$ for experimentally measured and simulated $\mathrm{CD}$ spectra in the B region. The sign of the corresponding Cotton effect and its rotational strength are shown in parenthesis. The mean absolute deviation (MAD) and standard deviation (SD) were estimated for each functionals with respect to the corresponding experimental value.

\begin{tabular}{|c|c|c|c|c|c|c|c|c|}
\hline Complex & Exp. & BH\&HLYP & B3LYP & M06 & M06-2X & LC- $\omega$ HPBE & CAM-B3LYP & $\omega B 97 X-D$ \\
\hline \multirow{2}{*}{ A/L-Ala-OMe } & $425(+19.2)$ & $384(+10.6)$ & $406(+3.8)$ & $404(+7.8)$ & $384(+8.1)$ & $373(+7.6)$ & $385(+7.2)$ & $384(+6.5)$ \\
\hline & $429(-18.0)$ & $397(-17.4)$ & $432(-6.8)$ & $428(-13.1)$ & $406(-13.9)$ & $394(-15.2)$ & $407(-13.6)$ & $406(-13.6)$ \\
\hline \multirow{2}{*}{ A/L-Phe-OMe } & $423(+19.0)$ & $377(+27.1)$ & $405(+10.8)$ & $405(+8.5)$ & $385(+20.4)$ & $374(+20.2)$ & $385(+18.2)$ & $385(+17.3)$ \\
\hline & $429(-29.9)$ & $398(-53.1)$ & $431(-28.9)$ & $431(-38.7)$ & $407(-46.6)$ & $395(-45.3)$ & $408(-43.9)$ & $407(-42.8)$ \\
\hline \multirow{2}{*}{ A/L-Leu-OMe } & $422(+32.3)$ & $376(+12.0)$ & $396(+0.7)$ & $404(+3.5)$ & $385(+10.1)$ & $374(+8.0)$ & $385(+8.1)$ & $385(+7.8)$ \\
\hline & $427(-36.5)$ & $397(-18.4)$ & $427(-11.2)$ & $428(-13.3)$ & $406(-15.2)$ & $395(-15.5)$ & $407(-15.0)$ & $407(-15.0)$ \\
\hline \multirow{2}{*}{ A/S-leucinol } & \multirow{2}{*}{$431(-3.6)$} & $377(+28.0)$ & $408(+15.2)$ & $407(+24.4)$ & $386(+24.4)$ & $376(+25.9)$ & $388(+23.4)$ & $386(+21.6)$ \\
\hline & & $398(-26.9)$ & $434(-13.5)$ & $431(-22.3)$ & $408(-23.1)$ & $397(-24.8)$ & $409(-22.1)$ & $409(-22.6)$ \\
\hline \multirow{2}{*}{ B/L-Phe-OMe } & \multirow{2}{*}{$425(-3.8)$} & $376(+17.7)$ & $403(+8.2)$ & $403(+13.8)$ & $384(+13.9)$ & $374(+14.0)$ & $385(+12.9)$ & $384(+12.9)$ \\
\hline & & $397(-26.4)$ & $428(-18.1)$ & $429(-20.8)$ & $406(-24.8)$ & $394(-23.7)$ & $407(-23.2)$ & $406(-22.8)$ \\
\hline \multirow{3}{*}{ C/L-Phe-OMe } & \multirow{3}{*}{$411(-7.5)$} & $378(-11.0)$ & $373(-1.3)$ & $406(-6.5)$ & $387(-12.1)$ & $377(-11.3)$ & $389(-10.3)$ & $388(-10.1)$ \\
\hline & & & $383(-1.1)$ & & & & & \\
\hline & & & $407(-5.3)$ & & & & & \\
\hline MAD & & $36(14.3)$ & $13(11.5)$ & $11(4.4)$ & $28(4.4)$ & $39(1.0)$ & $27(1.1)$ & $28(0.5)$ \\
\hline SD & & $10(8.5)$ & $9(5.5)$ & $8(2.9)$ & $11(3.7)$ & $10(0.6)$ & $11(0.8)$ & $11(0.4)$ \\
\hline
\end{tabular}

complexes: A/L-Ala-OMe, A/L-Leu-OMe, and A/L-Phe-OMe (Figure $3 a$ and $c$ and Figure S2a). But, in contrast to the experimental data, the simulated $C D$ spectra of $A / S$-leucinol and $\mathrm{B} / \mathrm{L}-\mathrm{Phe}-\mathrm{OMe}$ have also bisignate $\mathrm{CD}$ signals (Figure $3 \mathrm{~b}$ and Figure S2e). The experimental CD spectrum of B/L-Phe-OMe (Figure S2e) shows a weak negative peak with an intensity of only $3.8 \mathrm{cgs}$, but in the simulated spectrum the positive peak is about two times weaker than the negative one. Indeed, this small positive peak might not be observed in the experimental spectrum due to the noise level. Finally, the last simulated $C D$ spectrum of C/L-Phe-OMe has only one negative peak (Figure 3d), which agrees with the experimental data.

The LC- $\omega$ HPBE and BH\&HLYP functionals underestimate the absorption maxima wavelength values more than other functionals by $30-50 \mathrm{~nm}$ (largest MAD values for the peak positions, Table 1). This agrees with the previous observation of Rudolph and Autschbach ${ }^{89}$ that the accuracy of rangeseparated hybrid functionals does not outperform the global hybrid functionals in all cases. Also, it was reported that TDDFT calculations are sensitive to the fraction of exact exchange in the functionals. $39,40,84,86,123$ In our case, the increase of Hartree Fock fraction in the functionals shifts the CD spectra to the high energy region (for example BH\&HLYP versus B3LYP and M06-2X versus M06; Table 1, Figure S2). The same tendency was observed for $\left[\mathrm{M}(\mathrm{L})_{3}\right]^{\mathrm{n+}}$ complexes by Rudolph and Autschbach ${ }^{89}$ and for a set of dyes by Goerigk et al. ${ }^{39}$

For all systems, the CD maxima/minima calculated using the M06 and B3LYP functionals showed the best agreement with the corresponding experimental values when the positions of the bands are considered (smallest MAD values for the peak positions, Table 1). However, in some cases the rotational strength was significantly underestimated. Deeper analysis of the simulated spectra revealed that the B3LYP and M06 functionals overestimated the number of excited states in the absorption region studied (Table S3). All other hybrid functionals placed two excited states as in the B-band region and in the Q-band region. Thus, to cover the whole absorption area of $350-600 \mathrm{~nm}$ only the first four excited states are needed. In contrast, to cover the $350-600 \mathrm{~nm}$ region using M06 (resp. B3LYP), 17-18 (resp. 20) excited states should be used for the hosts $A$ and $B$, and 10 (resp. 12) excited states for host C. Previously, it was found that the number of excited states generated per energy unit by hybrid functionals can differ from non-hybrid and range-separated functionals. ${ }^{39,89}$ Hence, Rudolph and Autschbach ${ }^{89}$ reported about fewer excited states, while Bary et al., ${ }^{124}$ Goerigk et al., ${ }^{39}$ and Brkljača et $a{ }^{73}$ found a larger number of excited states. The ability of 


\section{ARTICLE}
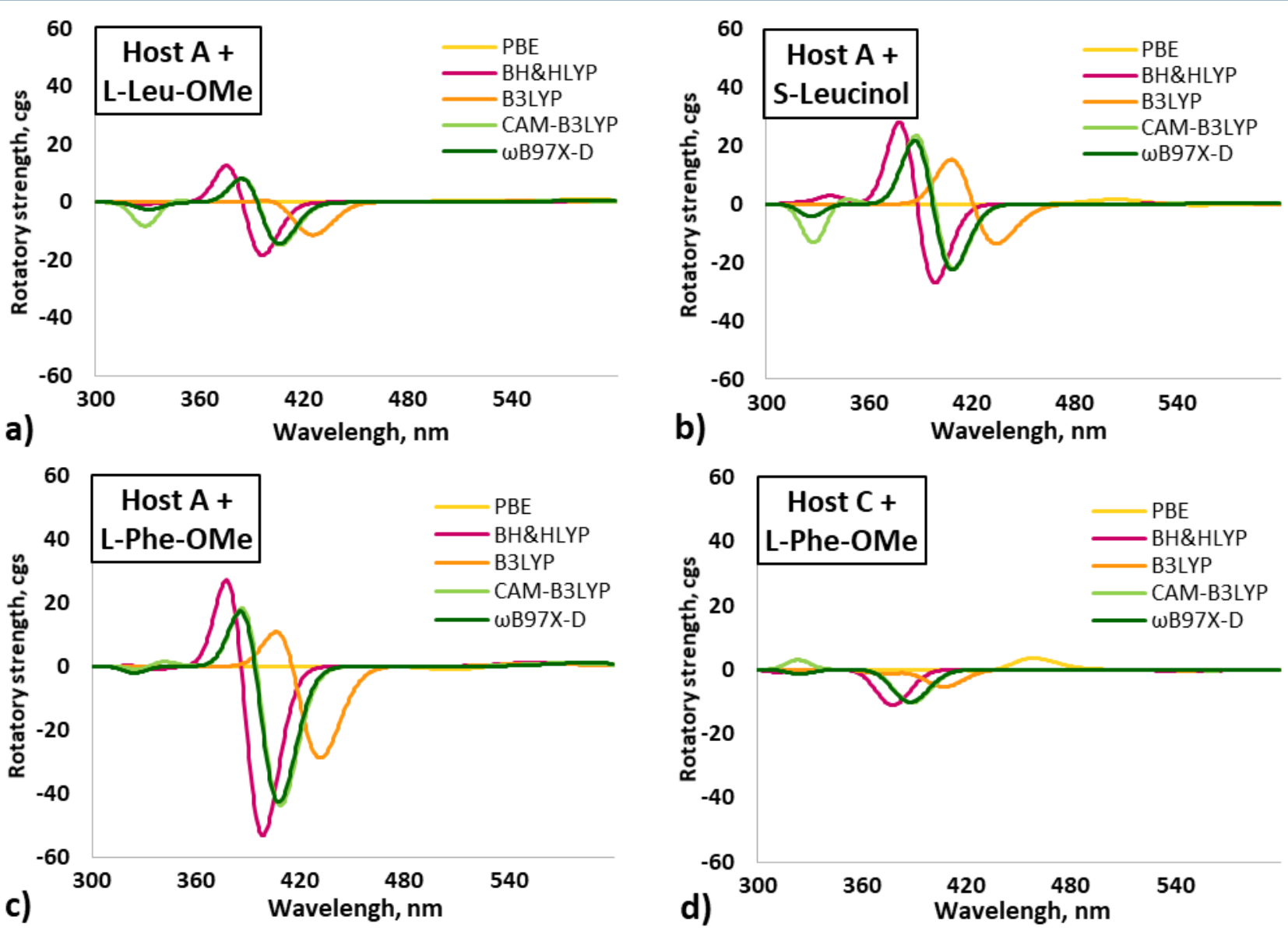

Figure 3. Simulated CD spectra calculated using different functionals, SMD solvent model and cc-pVDZ basis set of a) A/L-LeuOMe, b) A/S-Leucinol, c) A/L-Phe-OMe, d) C/L-Phe-OMe. The spectra simulated using M06, M06-2X and LC- $\omega$ HPBE functionals are shown in Figure $\mathrm{S} 2$.

hybrid functionals to create "spurious" excited states was explained by a low fraction of the exact exchange. Our results also confirmed this conclusion for both the B3LYP and M06 functionals.

Figure 4 shows the CD spectra simulated using the B3LYP and M06 functionals, including 6 and 20 first excited states, respectively. In addition, the spectra simulated using the $\omega B 97 X-D$ functional showed how other functionals performed in this region. Inclusion of 14 additional excited states practically did not change the rotational strength and the peak maxima/minima of the Cotton effects. A sole exception is A/LPhe-OMe (Figure $4 \mathrm{c}$ ), where the rotational strength of the positive band is significantly decreased using B3LYP and 20 excited states. Regardless of the number of excited states used to construct the $C D$ spectra, positive bands for $A / L-L e u-O M e$ and A/L-Phe-OMe were underestimated (Figure $4 a, c$ ).
Moreover, when 20 excited states were considered for the $C D$ spectra simulation with the host A (Figures $4 a-c$ and S3a), the number of predicted Cotton effects increased, and there were more peaks than experimentally measured. Hence, two additional peaks, not detected experimentally, appeared in the region of $320-380 \mathrm{~nm}$ in the simulated $C D$ spectra of complexes with the hosts $B$ and $C$ (Figures $4 d$ and S3e).

The CD spectra simulated using the M06-2X, CAM-B3LYP and $\omega B 97 D X-D$ functionals were very similar in the B-band region. All the absorption maxima/minima predicted using these functionals were found to be blue-shifted by $20-40 \mathrm{~nm}$ compared to the experimental data. ${ }^{22,125}$ The slightly less good agreement of the simulated wavelengths using the rangeseparated hybrid functionals was previously explained by a too large component of the exact exchange, which possibly leads to the trade-off of electron correlation. ${ }^{89}$ However, those three 
functionals were recommended for treatment of the systems with a strong charge transfer character, ${ }^{52}$ since the "traditional" hybrid functionals are less accurate in such cases. It should be noted that in contrast to the spectra simulated by M06 and B3LYP, the CD data obtained using the M06-2X, CAMB3LYP and $\omega B$ 97DX-D functionals retain the same tendency as the experimentally measured spectra. For example, Mizutani et al. ${ }^{46}$ noticed that the host A with aliphatic amino acid esters exhibited almost the same intensity, while aromatic amino acid esters induced asymmetric $C D$ with the lower energy peak being more intense. In the simulated spectra of $A$ and Laromatic complexes, the rotational strength of higher energy positive peaks are about 2 times smaller than that of the lower energy negative signals (Figures $3 \mathrm{c}$ ) and in the simulated spectra of host $A$ and aliphatic guests complexes, while the rotational strengths of positive and negative bands are similar (Figures 3a and S2a).

3.3 $3^{\circ}$ Simulation of the $\mathbf{3 0 0 - 3 5 0} \mathrm{nm}$ region. The simulated $C D$ spectra in the region $300-350 \mathrm{~nm}$ differ to a greater extent among the studied models (Figures 3 and S2). This agrees with observations by Rudolph and Autschbach that performance of different classes of the functionals varies in the low-, medium and high-energy ranges, since each spectral region are dominated by a particular type of excitation. ${ }^{89}$ However, the available experimental data do not allow a more detailed comparative analysis.

\section{$4^{\circ}$ Performance of basis sets}

Although, the selection of the basis set is not so critical compared to the choice of the functional in TD-DFT calculations, the size of the basis set has an influence on the accuracy of simulations. ${ }^{42,91}$ Previously, it was reported that the double-zeta basis set is sufficient for UV and CD spectral simulations. ${ }^{84,90}$ The results discussed above are also in agreement with this conclusion. The use of cc-pVDZ basis set gives reasonably well simulated spectra. However, there are some recommendations to use bigger basis sets for CD spectra simulations. ${ }^{87,103,104,112}$ To study the influence of basis set size on the simulated CD spectra, calculations using the cc-pVTZ basis set were carried out (Figures 5 and S4). Four functionals were chosen for this test: the most conventional B3LYP and three other functionals (M06-2X, CAM-B3LYP, and WB97DX-D), which showed the best agreement with the experimental data.
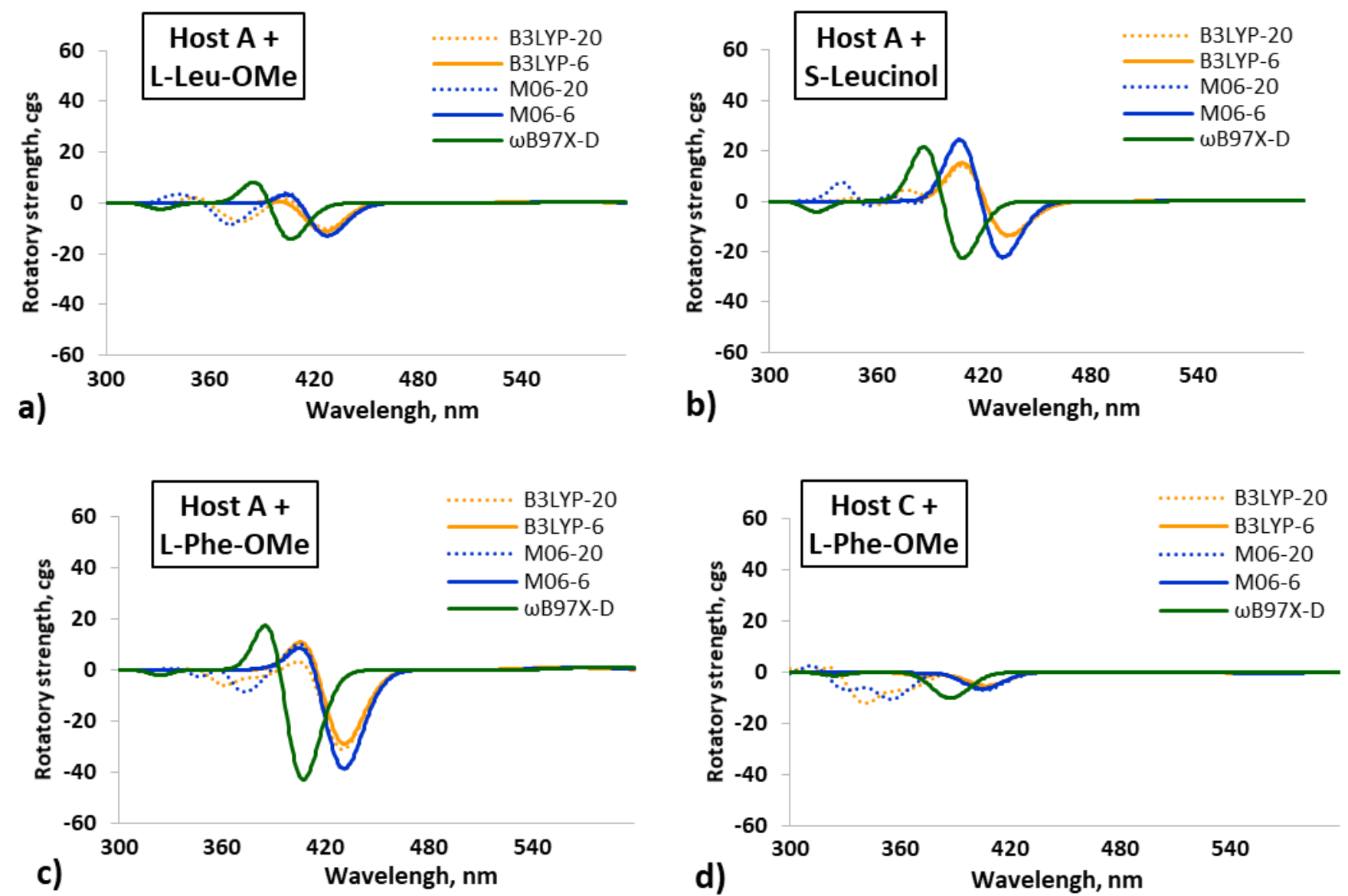

Figure 4. $C D$ spectra simulated for a) A/L-Leu-OMe, b) A/S-Leucinol, c) A/L-Phe-OMe, and d) C/L-Phe-OMe using the B3LYP, M06 and $\omega B 97 D X-D$ functionals. For the B3LYP and M06 functionals the CD spectra were constructed on the basis of 6 and 20 first excited states. 


\section{ARTICLE}

The use of a larger basis set significantly increased the time of calculations but did not improve notably the agreement with the experimental data. Thus, the absorption maxima predicted using the cc-pVTZ basis set were only $5-7 \mathrm{~nm}$ closer to the experimental values than those calculated using the cc-pVDZ basis set (Table S4). In fact, this observation agrees with previous findings. For example, $\mathrm{Si}$ and Yang reported some improvement (by $6 \mathrm{~nm}$ ) in the calculated absorption wavelengths, using the $6-311++G(2 d, 2 p)$ basis set instead of the $6-31 \mathrm{G}(\mathrm{d})$ one and B3LYP functional. ${ }^{90}$ Silva-Junior et al. ${ }^{126}$ also noticed systematic shifts to the low energy region on average by $7 \mathrm{~nm}$ in the excitation energies of one-electron transitions in benchmark of medium-sized organic molecules during the basis set extension from TZVP to aug-cc-pVTZ.

Although, the use of cc-pVTZ gives the absorption maxima closer to the experimental values by 6-7 nm, cc-pVDZ is superior to cc-pVTZ in predicting the rotational strength (Figures 5 and S4). Finally, the differences between the rotational strengths calculated using the dipole length and dipole velocity formalisms were considered. These two rotatory strength values are generally different, and the basis set quality can be estimated from their convergence. ${ }^{38,39,87,105,116}$ In the case of cc-pVDZ, the difference between rotatory strengths calculated using the dipole length and dipole velocity formalisms changes depending on the considered
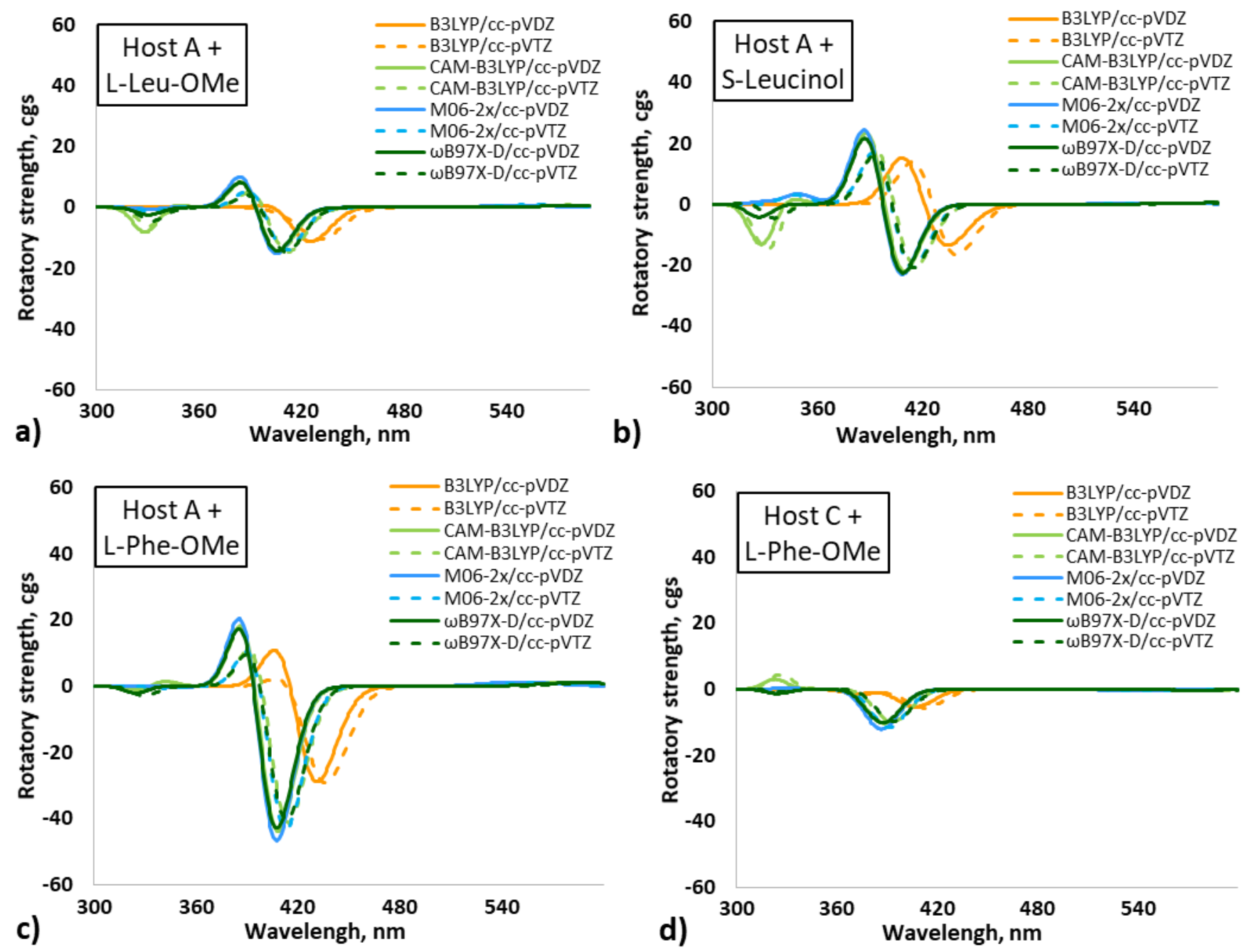

Figure 5. $C D$ spectra simulated for a) $A / L-L e u-O M e$, b) $A / S-$ Leucinol, c) A/L-Phe-OMe, and d) C/L-Phe-OMe using the B3LYP, M06-2X, CAM-B3LYP and wB97DX-D and cc-pVDZ and cc-pVTZ basis sets. 


\section{ARTICLE}

supramolecule (up to 2-5 cgs; Table S4). Similar difference in the calculated rotatory strengths was named "quite small" by $\mathrm{Si}$ et al. ${ }^{90,116}$ in simulations of the CD spectra of dinuclear zirconium complexes and zinc complexes. However, Li et al. ${ }^{116}$ recommended to use a larger basis set for CD spectra simulations of aromatic organic molecules with the same difference between the rotatory strengths calculated using the dipole length and dipole velocity formalisms. For the cc-pVTZ basis set, this difference was significantly smaller being just 1 cgs or even less (Table S4), hence confirming stability of this basis set, excepting for the calculations performed using M06-2X, where this value increased up to $8 \mathrm{cgs}$.

\section{$5^{\circ}$ Influence of the solvent}

The experimental spectra presented here were measured in a chloroform solution. Therefore, the CD spectra simulations were carried out both in a gas phase and in chloroform to rationalize the corresponding solvent effect (Figures 6 and S5). To include implicitly the solvent effects, TD-DFT single-point
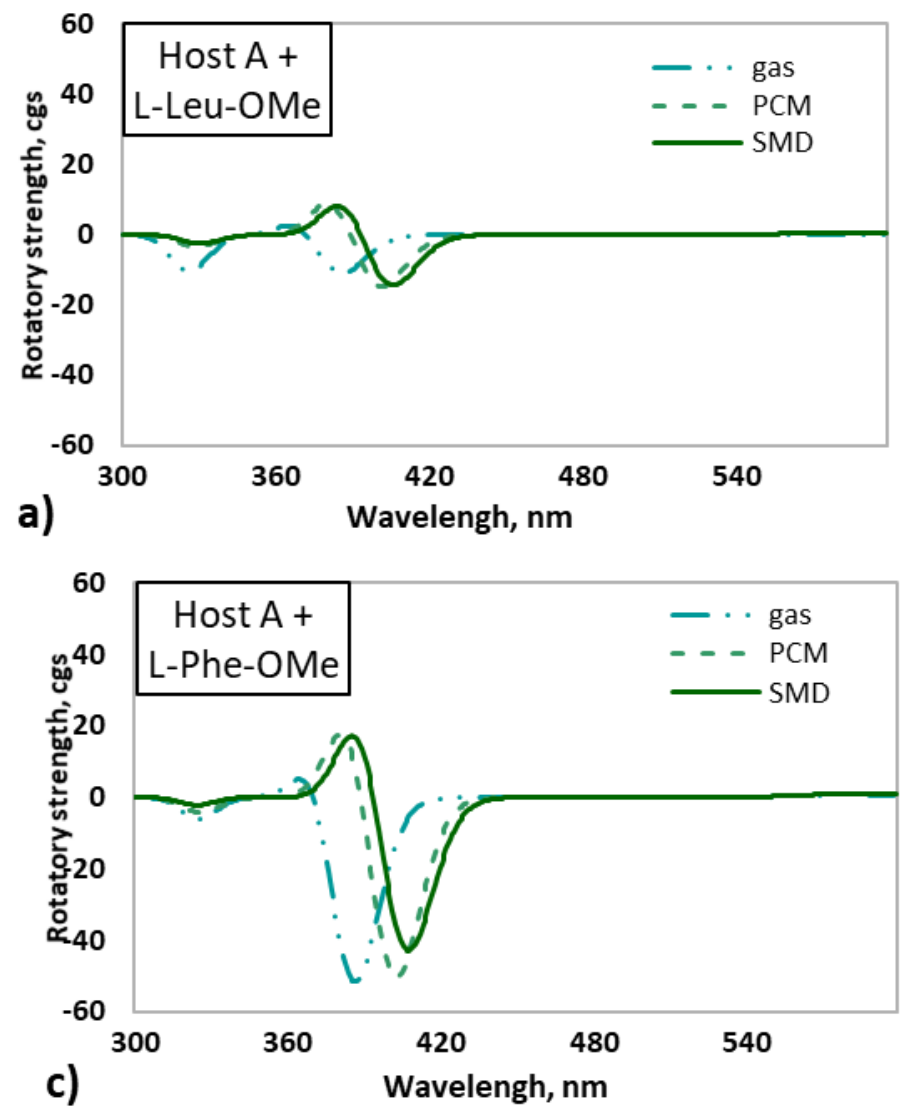

calculations were performed using the Polarizable Continuum Model (PCM) and the Solvation Model based on Density (SMD). Previously, it was reported that simulated CD spectra are highly sensitive to the solvent used, even up to a change in the signal sign. ${ }^{38,107,115,116,127}$ However, there are other examples stating that inclusion of the solvent effects did not improve the agreement with the measured spectra. 88,90

In the present study, it was found that compared to the experimental data, the excitation energies of the $B$ bands calculated in a gas phase were systematically shifted to higher energy by about 40-55 $\mathrm{nm}$ (Table S5). Upon using the PCM continuum model the shifts became smaller (30-40 nm), while the best matching values (25-35 nm) were achieved using the SMD continuum model. This observation agrees with the conclusion of Hoffmann et al. ${ }^{128}$ that, if the ground state structures are similar, the TD-DFT results will be very comparable and the solvation models have small influence.
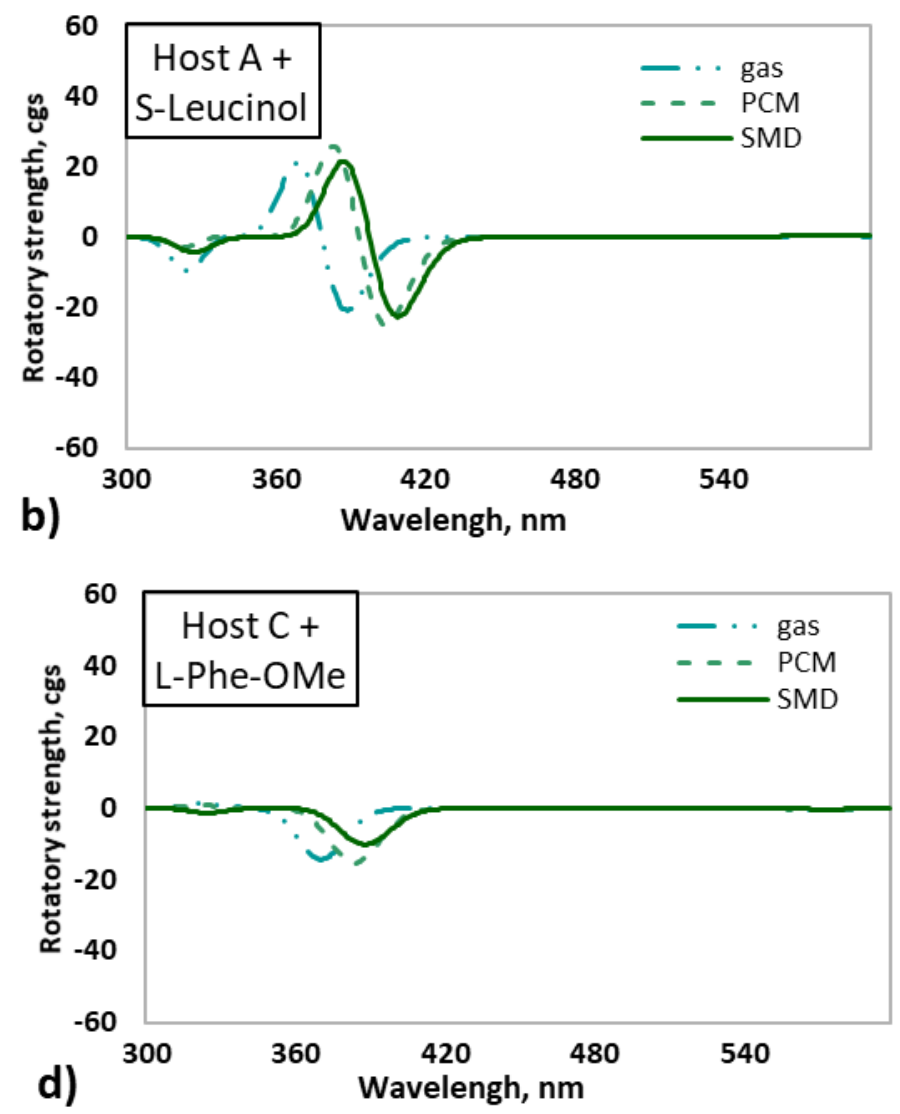

Figure 6. CD spectra simulated for a) Host A/L-Leu-OMe, b) Host A/S-Leucinol, c) Host A/L-Phe-OMe, and d) Host C/L-Phe-OMe using $\omega B 97 D X-D / c c-p V D Z$ in a gas phase and in chloroform using the PCM and SMD solvent models. 

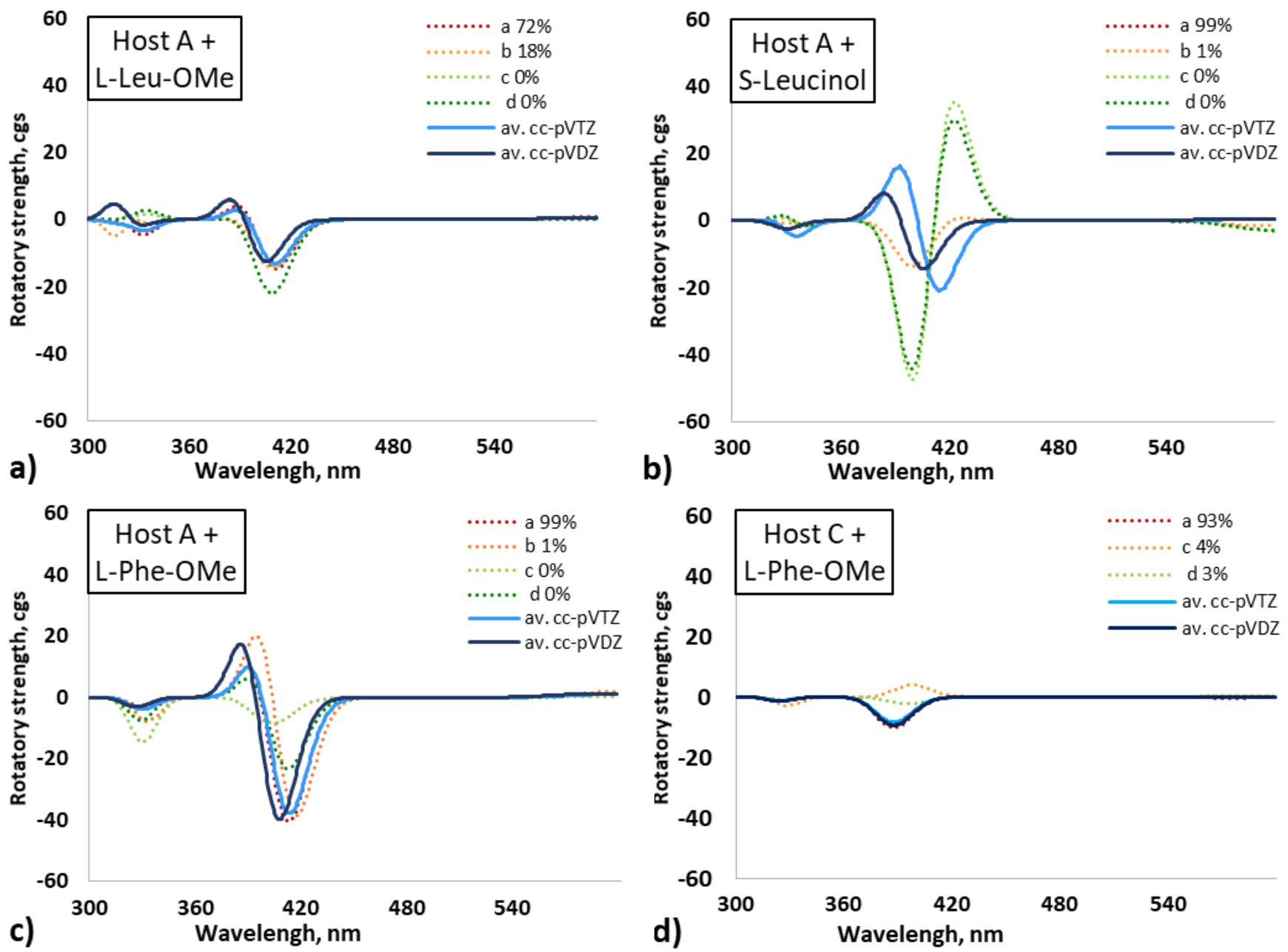

Figure 7. Simulated $C D$ spectra of the complexes with varying conformations of the guests (a-d, see Table $S 1$ ) and average $C D$ spectra calculated using the cc-pVDZ and cc-pVTZ basis sets for a) A/L-Leu-OMe, b) A/S-Leucinol, c) A/L-Phe-OMe, and d) C/L-PheOMe. Simulated spectra of the lowest-energy conformer (red dots) are not clearly seen because they coincide with the average CD spectra calculated using the cc-pVTZ basis set. Geometries of all considered conformers are given in Supporting Information.

However, it was also reported that in the case of copper(I) guanidine-quinoline cation, the PCM results were slightly closer to the experimental data. In contrast, the SMD model had a better agreement with the measured UV spectra for copper(II) guanidine-quinoline cation. ${ }^{128}$

It is also worth noting that in the simulated spectra of $A / L$-LeuOMe, A/L-Ala-OMe, A/L-Phe-OMe, and B/L-Phe-OMe (Figures 6 and $\mathrm{S} 5$ ), the positive peaks were significantly smoothed out in the gas phase. However, changing the solvent models did not have a strong effect on the intensities of the simulated peaks, although some differences of up to 5 cgs were observed. Based on these data it can be concluded that using the SMD solvent model slightly improved the agreement with experimental data.

\section{$6^{\circ}$ Influence of the guest conformation on CD spectra}

It is well known that $C D$ spectra are very sensitive to the conformations of the investigated molecule. ${ }^{88,129-133}$ There are reported situations where $C D$ spectra were drastically changed or even inverted because of the conformational changes. ${ }^{112,134}$ For the complexes with the host A, several different guesses for the initial geometry always resulted in the optimized structures presenting an hydrogen bond between the hydroxyl group on one naphtyl substituent and the carbonyl group of the ester on the guest (for the most stable conformer: $\mathrm{H}$...O = $1.865 \AA$ for L-Ala-OMe, $1.800 \AA$ for L-Leu-OMe, $1.816 \AA$ for LPhe-OMe, see Table S1 and file Geom.xyz) or with the hydroxyl group of leucinol $(\mathrm{H} . . . \mathrm{O}=1.831 \AA$ ). Interestingly, in the case of leucinol, the corresponding hydrogen bond is less stable $(\mathrm{H}$...O $=1.942 \AA$ for conformer $\mathbf{b}$ ). In the cases of hosts $\mathrm{B}$ and $\mathrm{C}$, where such hydrogen bonds are not possible, the most stable conformer presented a distorted stacking interaction between the phenyl ring on the guest and one pyrrole ring of the porphyrin. The centroid-centroid distance between the phenyl and pyrrole rings is $4.21 \AA$ (resp. $4.03 \AA$ ) for the host $B$ (resp. host $C$ ). The angle between the plane of the phenyl group and the plane of the pyrrole ring is $18.4^{\circ}$ (resp. $28.4^{\circ}$ ) for the host B (resp. host C). This is indicative of a significant stacking 
interaction between the phenyl ring on the guest and the porphyrin ring of the host. However, this stacking interaction is of a lesser strength than other possible interaction, such as $\mathrm{H}$ bonding, as illustrated by the geometry of the most stable conformer for L-Phe-OMe with the host A.

Similarly, to the published studies, in our case the guest conformation plays a critical role in determining the shape of the $C D$ spectra, ${ }^{135}$ but in the case of all complexes studied the lowest-energy conformer made up more than $70 \%$ of the Boltzmann distribution. Thus, the CD spectra of the lowestenergy conformers in Figure 7 coincided with the average curve simulated using the cc-pVTZ basis set.

In agreement with the Gouterman's four-orbital Linear Combinations of Atomic Orbitals - Molecular Orbitals (LCAO$\mathrm{MO})$ model, ${ }^{136}$ the electronic transitions in the $\mathrm{Q}$ and $\mathrm{B}$ regions are developed on the HOMO-1, HOMO, LUMO, and LUMO+1 orbitals. In the case of the $Q$ region only the above-mentioned four orbitals participate (Table S6), while for the $B$ region the lower-lying occupied MOs have minor contributions. Considering that each of the four first excited states are composed of different transitions between the occupied and empty MOs, a Natural Transition Orbital analysis for the third and fourth excited states was carried out. In Figure 8 the third and fourth excitations for A/L-Phe-OMe are shown. In the third excited state the electronic transitions $\psi_{\text {номо-1 }} \rightarrow \psi_{\text {'Lumo }}$ and $\psi_{\text {HOMO-1 }} \rightarrow \psi_{\text {LUMO+1 }}^{\prime}$ (with the coefficients of 0.531 and 0.465 , respectively) take place. In the fourth excited state the associated hole involves significant contributions from both $\psi_{\text {Hомо-1 }}$ and $\psi_{\text {номо }}$ and this excited state is approximately

\section{Excited state 3}
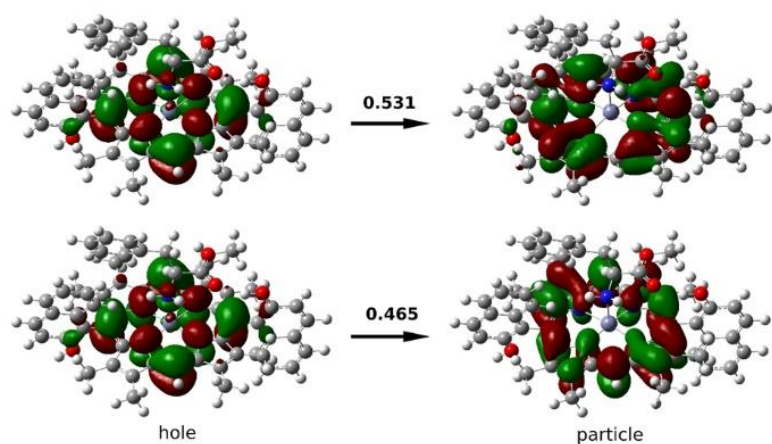

Excited state 4

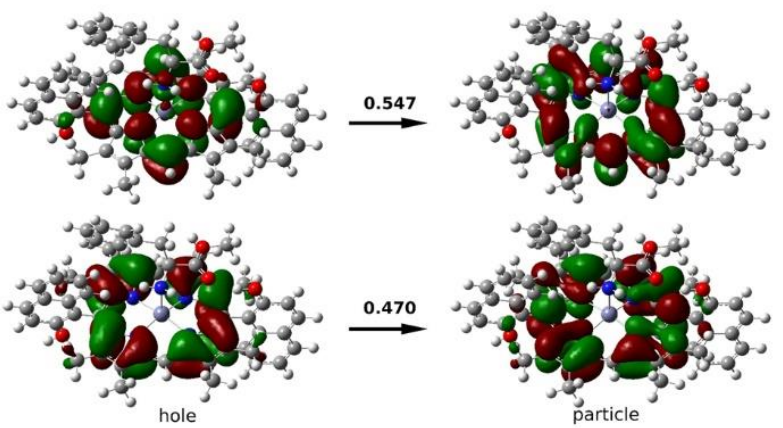

Figure 8. Natural Transition Orbital analysis for A/L-Phe-OMe. described as $0.547\left(\psi_{\text {номо- }} \rightarrow \psi_{\text {LUMO }+1}\right)+0.470\left(\psi_{\text {номо }} \rightarrow\right.$

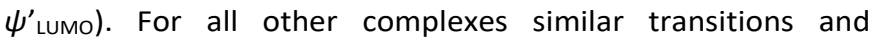
redistribution of the electronic density were observed (Figure S7-S9). Thus, in the ground state the electron density is mainly situated on the porphyrin plane, and its smaller components are on the zinc cation, nitrogen atom of the guest, and both naphthyl rings. Upon excitation to the third and fourth excited states, the electronic density shifts from the zinc cation and coordinated nitrogen of the guest to the porphyrin plane, indicating a charge transfer character. Moreover, in various complexes, the $\mathrm{N}_{\text {host }}-\mathrm{Zn}-\mathrm{N}_{\text {guest }}$ bend angle varies from $84^{\circ}$ to $107^{\circ}$ and in all systems the $N_{1}-Z n-N_{\text {guest }}$ and $N_{2}-Z n-N_{\text {guest }}$ angles differ from each other (Figure 9), indicating an asymmetric (with respect to the porphyrin plane) coordination of the nitrogen atom. However, a correlation between this asymmetric coordination and the shape of the $C D$ spectra could not be found.

Binding of a guest causes not only redistribution of the electron density, but also distorts the porphyrin plane due to noncovalent interactions. As it was already shown by Kiefl et al. ${ }^{137}$ heme deformations are strongly correlated with the rotational strengths. To estimate the distortion of the porphyrin plane induced by complexation with a guest, two dihedral angles $\mathrm{C}_{\mathrm{a}}-\mathrm{N}_{\mathrm{opp}}-\mathrm{N}_{\mathrm{opp}}-\mathrm{C}_{\mathrm{a}^{\prime}}$ used to characterize the distortion of porphyrins ${ }^{1}$ were considered (Figure 9). In Table 2 the corresponding dihedral angles and two bend angles $\left(\mathrm{N}_{1}-\mathrm{Zn}\right.$ $\mathrm{N}_{\text {guest }}$ and $\left.\mathrm{N}_{2}-\mathrm{Zn}-\mathrm{N}_{\text {guest }}\right)$ are given. In the conformers $\mathbf{a}$ and $\mathbf{b}$ of A/L-Ala-OMe, the $\mathrm{N}_{1}-\mathrm{Zn}-\mathrm{N}_{\text {guest }}$ and $\mathrm{N}_{2}-\mathrm{Zn}-\mathrm{N}_{\text {guest }}$ bend angles

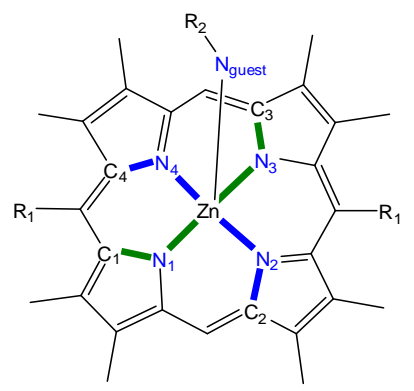

Figure 9. Bend and dihedral angles used for description of the geometry of the complexes.

Table 2. Characteristics of geometry and $C D$ spectra in the $B$ region for A/L-Ala-OMe and C/L-Phe-OMe

\begin{tabular}{|l|l|l|l|l|l|l|}
\hline \multirow{5}{*}{} & Supramolecule & \multicolumn{2}{|c|}{$\begin{array}{c}\text { Host A/ } \\
\text { L-Ala-OMe }\end{array}$} & \multicolumn{3}{c|}{$\begin{array}{c}\text { Host C/ } \\
\text { L-Phe-OMe }\end{array}$} \\
\cline { 2 - 7 } & Conformer & $\mathbf{a}$ & $\mathbf{b}$ & $\mathbf{a}$ & $\mathbf{b}$ & $\mathbf{c}$ \\
\cline { 2 - 7 } & $\mathbf{C D}$ data in B & +3.2 & -15.2 & -10.1 & +4.0 & -2.2 \\
region, cgs & $(388)$ & $(407)$ & $(388)$ & $(397)$ & $(395)$ \\
& -14.6 & & & & \\
& $(411)$ & & & & \\
\hline \multirow{5}{*}{ angles } & $\boldsymbol{\alpha}\left(\mathrm{C}_{1}-\mathrm{N}_{1}-\mathrm{N}_{3}-\mathrm{C}_{3}\right)$ & $-10.6^{\circ}$ & $-13.6^{\circ}$ & $-2.5^{\circ}$ & $-4.7^{\circ}$ & $-2.0^{\circ}$ \\
\cline { 2 - 8 } & $\left.\boldsymbol{\beta}\left(\mathrm{C}_{2}-\mathrm{N}_{2}-\mathrm{N}_{4}-\mathrm{C}_{4}\right)\right)$ & $4.8^{\circ}$ & $6.3^{\circ}$ & $-0.7^{\circ}$ & $6.7^{\circ}$ & $0.1^{\circ}$ \\
\cline { 2 - 8 } & $\boldsymbol{\gamma}\left(\mathrm{N}_{1}-\mathrm{Zn}_{-}-\mathrm{N}_{\text {guest }}\right)$ & $93^{\circ}$ & $94^{\circ}$ & $95^{\circ}$ & $96^{\circ}$ & $95^{\circ}$ \\
\cline { 2 - 7 } & $\boldsymbol{\delta}\left(\mathrm{N}_{2}-\mathrm{Zn}_{-} \mathrm{N}_{\text {guest }}\right)$ & $97^{\circ}$ & $97^{\circ}$ & $101^{\circ}$ & $98^{\circ}$ & $102^{\circ}$ \\
\hline
\end{tabular}


remained almost the same, but extent of the distortion of the porphyrin plane in these two conformers is different, resulting in negative Cotton effect for the conformer $\mathbf{b}$ and bisignate $(-/+)$ CD signal for the conformer a. (Table 2 and Figure S6a). In the case of $\mathrm{C} / \mathrm{L}-\mathrm{Phe}-\mathrm{OMe}$, the intensity of the $\mathrm{CD}$ band becomes weaker with decreasing the porphyrin plane distortion in the conformer $\mathbf{c}$ as compared to the conformer a (Table 2 and Figure 7). In the conformer $\mathbf{b}$, the distortion of the porphyrin plane is the largest, and the $C D$ signal of this conformer is positive in contrast to the previously considered conformers $a$ and $c$. However, the $\mathrm{N}_{1}-\mathrm{Zn}-\mathrm{N}_{\text {guest }}$ and $\mathrm{N}_{2}-\mathrm{Zn}-\mathrm{N}_{\text {guest }}$ bend angles are also changed, albeit less significantly. In other systems studied, no clear connection between the distortion of the porphyrin plane or variation of the $\mathrm{N}_{1}-\mathrm{Zn}-\mathrm{N}_{\text {guest }}$ and $\mathrm{N}_{2}$ $\mathrm{Zn}-\mathrm{N}_{\text {guest }}$ bend angles and the change in the CD spectra were found.

\section{Conclusion}

In the present work, $C D$ spectra for six supramolecular complexes were simulated using eight functionals (PBE, BH\&HLYP, B3LYP, M06, M06-2X, CAM-B3LYP, wB97X-D and LC$\omega \mathrm{HPBE}$ ), two basis sets (cc-pVDZ and cc-pVTZ), and two continuum solvent models (PCM and SMD). It was found that M06-2X, CAM-B3LYP, and WB97X-D overperformed other functionals in the CD spectra simulations, while B3LYP and M06 created additional "spurious" excited states, which reduced the agreement with the experimental data. A good correlation with the experimental spectra was achieved using the cc-pVDZ basis set. However, the accurate simulation of length and velocity rotational strengths needed larger TZVP basis sets. The use of continuum solvent models considerably improves the agreement with the experimental results with better performance of SMD, which systematically shifts the transition energies by 5-7 $\mathrm{nm}$ to low energy as compared to the PCM model. Calculations showed that the conformation of the chiral guest plays an essential role in induced CD spectra of mono zinc porphyrins, as a result of different deformation of the porphyrin plane in various conformers. However, in the complexes studied, the lowest energy conformer constituted at least $70 \%$ of the Boltzmann distribution; therefore, its $C D$ spectrum was already in good agreement with the experimental data. Essentially, these findings can be further expanded to other existing and new chiral supramolecular systems to find a more general and efficient approach for computer simulation of chiroptical properties.

\section{Conflicts of interest}

There are no conflicts of interest to declare.

\section{Acknowledgements}

VB acknowledges the start-up research grant (YZZ16005) from South-Central University for Nationalities. RA acknowledges the Estonian Research Council for financial support through Grant PRG399, the ERDF through the CoE 2014-2020.4.01.150013. IO acknowledges support from Estonian ministry of education and research (Grant No. PUTJD749).

Computations were performed on the HPC cluster at Tallinn University of Technology, which is part of the ETAIS project.

\section{References}

1 M. O. Senge, S. A. MacGowan, J. M. O'Brien, Chem. Commun., 2015, 51, 17031-17063.

2 D. Voet, J. G. Voet, Biochemistry, Wiley, 2004.

3 G. Bottari, O. Trukhina, M. Ince, T. Torres, Coord. Chem. Rev., 2012, 256, 2453-2477.

4 M. V. Martínez-Díaz, G. de la Torre, T. Torres, Chem. Commun., 2010, 46, 7090-7108.

J. C. Barona-Castaño, C. C. Carmona-Vargas, T. J. Brocksom, K. T. De Oliveira, M. Graça, P. M. S. Neves, M. Amparo, F. Faustino, Molecules, 2016, 21, 310.

S. Sahu, D. P. Goldberg, J. Am. Chem. Soc., 2016, 138, 11410-11428.

7

W. Zhang, W. Lai, R. Cao, Chem. Rev., 2017, 117, 37173797.

8

C. M. B. Carvalho, T. J. Brocksom, K. T. de Oliveira, Chem. Soc. Rev., 2013, 42, 3302-3317.

9 B. Meunier, Chem. Rev., 1992, 92, 1411-1456. C.-M. Che, V. K.-Y. Lo, C.-Y. Zhou, J.-S. Huang, Chem. Soc. Rev., 2011, 40, 1950-1975.

11 N. Chaudhri, M. Sankar, RSC Adv., 2015, 5, 3269-3275.

12 G. A. Hembury, V. V. Borovkov, Y. Inoue, Chem. Rev., 2008, 108, 1-73.

13 R. Paolesse, S. Nardis, D. Monti, M. Stefanelli, C. Di Natale, Chem. Rev., 2017, 117, 2517-2583. Y. Ding, W.-H. Zhu, Y. Xie, Chem. Rev., 2017, 117, 22032256.

P. J. Chmielewski, M. Siczek, M. Stępień, Chem. - A Eur. J., 2015, 21, 2547-2559.

V. V. Borovkov, Symmetry (Basel)., 2010, 2, 184-200.

V. V. Borovkov, Symmetry (Basel)., 2014, 6, 256-294.

V. V. Borovkov, Y. Inoue, Eur. J. Org. Chem, 2009, 189-197.

V. V. Borovkov, Y. Inoue, in Supramolecular Chirality, eds. M. Crego-Calama and, D. N. Reinhoudt, Springer Berlin Heidelberg, Berlin, Heidelberg, 2006, pp. 89-146.

G. Geraci, L. J. Parkhurst, Methods Enzymol, 1981, 76, 262 275.

F. Ishiwari, K. Fukasawa, T. Sato, K. Nakazono, Y. Koyama, T. Takata, Chem. - A Eur. J., 2011, 17, 12067-12075.

M. Balaz, M. De Napoli, A. E. Holmes, A. Mammana, K. Nakanishi, N. Berova, R. Purrello, Angew. Chemie, 2005, 117, 4074-4077.

H. Lu, N. Kobayashi, Chem. Rev., 2016, 116, 6184-6261.

S. Ito, S. Hiroto, N. Ousaka, E. Yashima, H. Shinokubo, Chem. - An Asian J., 2016, 11, 936-942.

X. Huang, N. Fujioka, G. Pescitelli, F. E. Koehn, R. T. Williamson, K. Nakanishi, N. Berova, J. Am. Chem. Soc., 2002, 124, 10320-10335. 
ChemPhysChem, 2006, 7, 1235-1240. 2016, 55, 3730-3737. 16761-16769. Eur. J., 2020, 26, 3515-3518. 2020, 32, 2272-2281. Inorg. Chem., 2017, 56, 3849-3860. 2539. 2007, 111, 12057-12068. Phys., 2009, 11, 4611-4620. 388, 110-119. 2071-2085. 2010, 12, 12697-12701. Chem., 1993, 32, 2072-2077. Chem., 1994, 33, 3558-3566. Chem. A, 2012, 116, 778-783. 981, 73-85. 15, 9081-9094. 1253-1268. Chem. Acc., 1997, 97, 119-124.
G. Pescitelli, T. Bruhn, Chirality, 2016, 28, 466-474.

T. Kim, J. Oh, H.-W. Jiang, T. Tanaka, A. Osuka, D. Kim, Phys. Chem. Chem. Phys., 2016, 18, 23105-23110.

W. Lu, H. Yang, X. Li, C. Wang, X. Zhan, D. Qi, Y. Bian, J. 58 Jiang, Inorg. Chem., 2017, 56, 8223-8231.

Z. Han, L. Li, B. Shi, X. Fang, Y. Wang, C. Hu, Inorg. Chem., 59

S. Wu, Z.-Z. Yin, D. Wu, Y. Tao, Y. Kong, Langmuir, 2019, 35, 60

M. Gaeta, G. Sortino, R. Randazzo, I. Pisagatti, A. Notti, M. E. Fragalà, M. F. Parisi, A. D'Urso, R. Purrello, Chem. - A

S. Tannir, L. Levintov, M. A. Townley, B. M. Leonard, J. Kubelka, H. Vashisth, K. Varga, M. Balaz, Chem. Mater.,

B. Saha, S. A. Ikbal, A. G. Petrovic, N. Berova, S. P. Rath,

B. Saha, A. G. Petrovic, A. Dhamija, N. Berova, S. P. Rath, Inorg. Chem., 2019, 58, 11420-11438.

T. D. Crawford, Theor. Chem. Acc., 2006, 115, 227-245.

C. Diedrich, S. Grimme, J. Phys. Chem. A, 2003, 107, 2524-

T. D. Crawford, M. C. Tam, M. L. Abrams, J. Phys. Chem. A,

L. Goerigk, J. Moellmann, S. Grimme, Phys. Chem. Chem.

D. Jacquemin, V. Wathelet, E. A. Perpète, C. Adamo, J. Chem. Theory Comput., 2009, 5, 2420-2435.

M. Pecul, K. Ruud, T. Helgaker, Chem. Phys. Lett., 2004,

A. C. Tsipis, Coord. Chem. Rev., 2014, 272, 1-29.

F. Neese, Coord. Chem. Rev., 2009, 253, 526-563.

D. Jacquemin, E. A. Perpète, I. Ciofini, C. Adamo, R. Valero, Y. Zhao, D. G. Truhlar, J. Chem. Theory Comput., 2010, 6,

R. Li, J. Zheng, D. G. Truhlar, Phys. Chem. Chem. Phys.,

T. Mizutani, T. Ema, T. Yoshida, Y. Kuroda, H. Ogoshi, Inorg.

T. Mizutani, T. Ema, T. Yoshida, T. Renne, H. Ogoshi, Inorg.

P. Štěpánek, V. Andrushchenko, K. Ruud, P. Bouř, J. Phys.

J. Barbee, A. E. Kuznetsov, Comput. Theor. Chem., 2012, 70

A. Zhang, L. Kwan, M. J. Stillman, Org. Biomol. Chem., 2017, 71

R. E. Haddad, S. Gazeau, J. Pécaut, J.-C. Marchon, C. J. 72 Medforth, J. A. Shelnutt, J. Am. Chem. Soc., 2003, 125,

K. Eichkorn, O. Treutler, H. Öhm, M. Häser, R. Ahlrichs, Chem. Phys. Lett., 1995, 240, 283-290.

K. Eichkorn, F. Weigend, O. Treutler, R. Ahlrichs, Theor.

M. Sierka, A. Hogekamp, R. Ahlrichs, J. Chem. Phys., 2003 118, 9136-9148.
A. D. Becke, Phys. Rev. A, 1988, 38, 3098-3100.

J. P. Perdew, Phys. Rev. B, 1986, 33, 8822-8824.

S. Grimme, J. Antony, S. Ehrlich, H. Krieg, J. Chem. Phys., 2010, 132, 154104.

A. Schäfer, H. Horn, R. Ahlrichs, J. Chem. Phys., 1992, 97, 2571-2577.

R. Ahlrichs, M. Bär, M. Häser, H. Horn, C. Kölmel, Chem. Phys. Lett., 1989, 162, 165-169.

TURBOMOLE V6.5 2013, a development of University of Karlsruhe, Forschungszentrum Karlsruhe $\mathrm{GmbH}$, 19892007, TURBOMOLE GmbH, since 2007; available from http://www.turbomole.com.

F. Furche, J. P. Perdew, J. Chem. Phys., 2006, 124, 44103.

L. Goerigk, S. Grimme, Phys. Chem. Chem. Phys., 2011, 13, 6670-6688.

S. Grimme, S. Ehrlich, L. Goerigk, J. Comput. Chem., 2011, 32, 1456-1465.

F. Weigend, Phys. Chem. Chem. Phys., 2006, 8, 1057-1065. J. Andelm, C. Kölmel, A. Klamt, J. Chem. Phys., 1995, 103, 9312-9320.

Gaussian 16, Revision A.03, M. J. Frisch, G. W. Trucks, H. B. Schlegel, G. E. Scuseria, M. A. Robb, J. R. Cheeseman, G. Scalmani, V. Barone, G. A. Petersson, H. Nakatsuji, X. Li, M. Caricato, A. V. Marenich, J. Bloino, B. G. Janesko, R. Gomperts, B. Mennucci, H. P. Hratchian, J. V. Ortiz, A. F. Izmaylov, J. L. Sonnenberg, D. Williams-Young, F. Ding, F. Lipparini, F. Egidi, J. Goings, B. Peng, A. Petrone, T. Henderson, D. Ranasinghe, V. G. Zakrzewski, J. Gao, N. Rega, G. Zheng, W. Liang, M. Hada, M. Ehara, K. Toyota, R. Fukuda, J. Hasegawa, M. Ishida, T. Nakajima, Y. Honda, O. Kitao, H. Nakai, T. Vreven, K. Throssell, J. A. Montgomery, J. J. E. Peralta, F. Ogliaro, M. J. Bearpark, J. J. Heyd, E. N. Brothers, K. N. Kudin, V. N. Staroverov, T. A. Keith, R. Kobayashi, J. Normand, K. Raghavachari, A. P. Rendell, J. C. Burant, S. S. Iyengar, J. Tomasi, M. Cossi, J. M. Millam, M. Klene, C. Adamo, R. Cammi, J. W. Ochterski, R. L. Martin, K. Morokuma, O. Farkas, J. B. Foresman, and D. J. Fox, Gaussian, Inc., Wallingford CT, 2016.

R. Bauernschmitt, R. Ahlrichs, Chem. Phys. Lett., 1996, 256, 454-464.

R. E. Stratmann, G. E. Scuseria, M. J. Frisch, J. Chem. Phys., 1998, 109, 8218-8224.

M. E. Casida, C. Jamorski, K. C. Casida, D. R. Salahub, J. Chem. Phys., 1998, 108, 4439-4449.

M. J. G. Peach, P. Benfield, T. Helgaker, D. J. Tozer, J. Chem. Phys., 2008, 128, 44118.

A. D. Dwyer, D. J. Tozer, Phys. Chem. Chem. Phys., 2010, 12, 2816-2818.

N. Kuritz, T. Stein, R. Baer, L. Kronik, J. Chem. Theory Comput., 2011, 7, 2408-2415.

73 Z. Brkljača, M. Mališ, D. M. Smith, A.-S. Smith, J. Chem. Theory Comput., 2014, 10, 3270-3279.

J. P. Perdew, K. Burke, M. Ernzerhof, Phys. Rev. Lett., 1996, 77, 3865-3868.

75 J. P. Perdew, K. Burke, M. Ernzerhof, Phys. Rev. Lett., 1997, 78, 1396.

76 A. D. Becke, J. Chem. Phys., 1993, 98, 1372-1377. 
C. Lee, W. Yang, R. G. Parr, Phys. Rev. B, 1988, 37, 785-789. B. Miehlich, A. Savin, H. Stoll, H. Preuss, Chem. Phys. Lett., 1989, 157, 200-206.

A. D. Becke, J. Chem. Phys., 1993, 98, 5648-5652.

Y. Zhao, D. G. Truhlar, Theor. Chem. Acc., 2008, 120, 215241.

81 T. Yanai, D. P. Tew, N. C. Handy, Chem. Phys. Lett., 2004 393, 51-57. J.-D. Chai, M. Head-Gordon, Phys. Chem. Chem. Phys., 2008, 10, 6615-6620.

T. M. Henderson, A. F. Izmaylov, G. Scalmani, G. E. Scuseria, J. Chem. Phys., 2009, 131, 44108. K. Nakano, T. Konishi, Y. Imamura, Chem. Phys., 2019, 518, 15-24.

D. Jacquemin, E. A. Perpète, G. E. Scuseria, I. Ciofini, C. Adamo, J. Chem. Theory Comput., 2008, 4, 123-135. C. A. Guido, D. Jacquemin, C. Adamo, B. Mennucci, J. Phys. Chem. A, 2010, 114, 13402-13410.

H. Jang, N. J. Kim, J. Heo, Comput. Theor. Chem., 2018, 1125, 63-68.

G. Pescitelli, S. Di Pietro, C. Cardellicchio, M. A. M. Capozzi, L. Di Bari, J. Org. Chem., 2010, 75, 1143-1154.

M. Rudolph, J. Autschbach, J. Phys. Chem. A, 2011, 115, 14677-14686.

Y. Si, G. Yang, RSC Adv., 2013, 3, 2241-2247.

A. Jesser, M. Rohrmüller, W. G. Schmidt, S. Herres-Pawlis, J. Comput. Chem., 2014, 35, 1-17.

M. Enamullah, A. K. M. R. Uddin, G. Pescitelli, R. Berardozzi, G. Makhloufi, V. Vasylyeva, A.-C. Chamayou, C. Janiak, Dalt. Trans., 2014, 43, 3313-3329.

Y.-M. Sang, L.-K. Yan, J.-P. Wang, N.-N. Ma, Z.-M. Su, J. Mol. Graph. Model., 2013, 44, 26-32.

G. Pescitelli, S. Lüdeke, A.-C. Chamayou, M. Marolt, V. Justus, M. Górecki, L. Arrico, L. Di Bari, M. A. Islam, I. Gruber, M. Enamullah, C. Janiak, Inorg. Chem., 2018, 57 , 13397-13408.

5 G. Maheut, A. Castaings, J. Pécaut, L. M. Lawson Daku, G. Pescitelli, L. Di Bari, J.-C. Marchon, J. Am. Chem. Soc., 2006, 128, 6347-6356.

A. Wang, Y. Wang, J. Jia, L. Feng, C. Zhang, L. Liu, J. Phys. Chem. A, 2013, 117, 5061-5072.

A. C. Gehrold, T. Bruhn, H. Schneider, U. Radius, G. Bringmann, Org. Lett., 2015, 17, 210-213.

T. Bruhn, F. Witterauf, D. C. G. Götz, C. T. Grimmer, M. Würtemberger, U. Radius, G. Bringmann, Chem. - A Eur. J., 2014, 20, 3998-4006.

M. Nagai, C. Kobayashi, Y. Nagai, K. Imai, N. Mizusawa, H. Sakurai, S. Neya, M. Kayanuma, M. Shoji, S. Nagatomo, J. Phys. Chem. B, 2015, 119, 1275-1287.

100 T. H. Dunning, J. Chem. Phys., 1989, 90, 1007-1023.

101 D. E. Woon, T. H. Dunning, J. Chem. Phys., 1993, 98, 13581371.

102 K. A. Peterson, D. E. Woon, T. H. Dunning, J. Chem. Phys. 1994, 100, 7410-7415.

103 G. Pescitelli, H. E. Kato, S. Oishi, J. Ito, A. D. Maturana, O. Nureki, R. W. Woody, J. Phys. Chem. B, 2014, 118, 1187311885.
A. Rizzo, O. Vahtras, J. Chem. Phys., 2011, 134, 244109.

I. Warnke, F. Furche, Wiley Interdiscip. Rev. Comput. Mol. Sci., 2012, 2, 150-166.

D. Jacquemin, C. Adamo, Int. J. Quantum Chem., 2012, 112, 2135-2141.

M. Pecul, K. Ruud, Adv. Quantum Chem., 2005, 50, 185212.

K. A. Nguyen, R. Pachter, J. Chem. Phys., 2001, 114, 1075710767.

R. F. Theisen, L. Huang, T. Fleetham, J. B. Adams, J. Li, J. Chem. Phys., 2015, 142, 94310.

S. Miertuš, E. Scrocco, J. Tomasi, Chem. Phys., 1981, 55, 117-129.

A. V. Marenich, C. J. Cramer, D. G. Truhlar, J. Phys. Chem. B, 2009, 113, 6378-6396.

S. Jahangir, K. M. Khan, W. M. F. Fabian, Comput. Theor. Chem., 2014, 1044, 15-23.

J. H. Cardellina, R. C. Vieira, V. Eccard, J. Skerry, V. Montgomery, Y. Campbell, V. Roxas-Duncan, W. Leister, C. A. LeClair, D. J. Maloney, D. Padula, G. Pescitelli, I. Khavrutskii, X. Hu, A. Wallqvist, L. A. Smith, ACS Med. Chem. Lett., 2011, 2, 396-401.

A. G. Martynov, J. Mack, A. K. May, T. Nyokong, Y. G. Gorbunova, A. Y. Tsivadze, ACS Omega, 2019, 4, 72657284.

G. Yang, J. Li, Y. Liu, T. L. Lowary, Y. Xu, Org. Biomol. Chem., 2010, 8, 3777-3783.

X.-C. Li, D. Ferreira, Y. Ding, Curr. Org. Chem., 2010, 14, 1678-1697.

GaussView, Version 6.1, Roy Dennington, Todd A. Keith, and John M. Millam, Semichem Inc., Shawnee Mission, KS, 2016.

M. Tsuge, L. Khriachtchev, J. Phys. Chem. A, 2015, 119, 2628-2635.

M. Ptaszek, in Fluorescence-Based Biosensors, ed. M. C. Morris, Academic Press, 2013, vol. 113, pp. 59-108.

J. Mack, Chem. Rev., 2017, 117, 3444-3478.

J. Šebek, P. Bouř, J. Phys. Chem. A, 2008, 112, 2920-2929.

V. V. Borovkov, A. Muranaka, G. A. Hembury, Y. Origane, G. V. Ponomarev, N. Kobayashi, Y. Inoue, Org. Lett., 2005, 7, 1015-1018.

M. Rudolph, T. Ziegler, J. Autschbach, Chem. Phys., 2011, 391, 92-100.

L. Di Bari, S. Guillarme, S. Hermitage, D. A. Jay, G. Pescitelli, A. Whiting, Chirality, 2005, 17, 323-331.

J. Fabian, Dye. Pigment., 2010, 84, 36-53.

M. R. Silva-Junior, M. Schreiber, S. P. A. Sauer, W. Thiel, J. Chem. Phys., 2010, 133, 174318.

V. V. Borovkov, G. A. Hembury, Y. Inoue, Angew. Chemie Int. Ed., 2003, 42, 5310-5314.

A. Hoffmann, M. Rohrmüller, A. Jesser, I. dos Santos Vieira, W. G. Schmidt and S. Herres-Pawlis, J. Comput. Chem., 2014, 35, 2146-2161.

T. Mori, Y. Inoue, S. Grimme, J. Org. Chem., 2006, 71, 9797-9806.

G. Kerti, T. Kurtán, A. Borbás, Z. B. Szabó, A. Lipták, L. Szilágyi, Z. Illyés-Tünde, A. Bényei, S. Antus, M. Watanabe, 
E. Castiglioni, G. Pescitelli, P. Salvadori, Tetrahedron, 2008, 64, 1676-1688.

131 S. Iwahana, H. lida, E. Yashima, G. Pescitelli, L. Di Bari, A. G. Petrovic, N. Berova, Chem. - A Eur. J., 2014, 20, 43864395.

132 L. Wang, G. Zhang, X. Wang, L. Wang, X. Liu, L. Jin, D. Xu, J. Mol. Struct., 2012, 1026, 71-77.

133 M. Kwit, J. Gawronski, D. R. Boyd, N. D. Sharma, M. Kaik, Org. Biomol. Chem., 2010, 8, 5635-5645

134 M. Nishizaka, T. Mori, Y. Inoue, J. Phys. Chem. A, 2011, 115, 5488-5495.

135 N. Konrad, D. Meniailava, I. Osadchuk, J. Adamson, M. Hasan, E. Clot, R. Aav, V. V. Borovkov, D. Kananovich, J. Porphyr. Phthalocyanines, DOI:10.1142/S108842461950192X.

136 M. Gouterman, Optical Spectra and Electronic Structure of Porphyrins and Related Rings. In the Porphyrins, Dolphin, D., Ed.; Academic Press: New York, NY, USA, 1978; Volume III, pp. 1-165.

137 C. Kiefl, N. Sreerama, R. Haddad, L. Sun, W. Jentzen, Y. Lu, Y. Qiu, J. Shelnutt, R. Woody, J. Am. Chem. Soc., 2002, 124, 3385-3394. 